OPEN ACCESS

Edited by:

Martin Reuter,

University of Bonn, Germany

Reviewed by:

Tino Zaehle,

Otto von Guericke University

Magdeburg, Germany

T. Celeste Napier,

Rush University, United States

${ }^{*}$ Correspondence:

Joshua A. Wilt

joshua.wilt@case.edu

Specialty section:

This article was submitted to Personality and Social Psychology,

a section of the journal

Frontiers in Psychology

Received: 17 December 2020

Accepted: 15 March 2021

Published: 30 July 2021

Citation:

Wilt JA, Merner AR, Zeigler J, Montpetite $M$ and Kubu CS (2021) Does Personality Change Follow Deep

Brain Stimulation in Parkinson's

Disease Patients?

Front. Psychol. 12:643277.

doi: 10.3389/fpsyg.2021.643277

\section{Does Personality Change Follow Deep Brain Stimulation in Parkinson's Disease Patients?}

\author{
Joshua A. Wilt ${ }^{1 *}$, Amanda R. Merner ${ }^{1,2}$, Jaclyn Zeigler $^{2}$, Michelle Montpetite ${ }^{2}$ and \\ Cynthia S. Kubu ${ }^{2,3}$
}

${ }^{1}$ Department of Psychological Sciences, Case Western Reserve University, Cleveland, OH, United States, ${ }^{2}$ Department of Neurology, Cleveland Clinic, Cleveland, OH, United States, ${ }^{3}$ Cleveland Clinic Lerner College of Medicine of Case Western Reserve University, Cleveland, $\mathrm{OH}$, United States

Deep Brain Stimulation (DBS) has emerged as a safe, effective, and appealing treatment for Parkinson's Disease (PD), particularly for improving motor symptoms (e. g., tremor, bradykinesia, and rigidity). However, concerns have been raised about whether DBS causes psychological changes, including changes to personality: characteristic and relatively stable patterns of affect, behavior, cognition, and desire. In this article, after first presenting some background information about PD and DBS, we examined evidence obtained from various empirical research methods (quantitative, qualitative, and mixed methods for evaluating patient valued characteristics) pertaining to whether DBS causes personality change. General limitations across research methods include a lack of randomized clinical trials and small sample sizes. We organized our review of findings according to different layers of personality variables: dispositional traits (including personality pathology), characteristic adaptations, and narrative identity. Though most work has been done on dispositional traits, there is not much evidence that dispositional traits change following DBS. Little work has been done on characteristic adaptations, but there is somewhat consistent evidence for positive perceived progress toward goals across a number of domains: routine activities, work, social/relational, and leisure. Nascent work on narrative identity holds promise for revealing issues around self-image that may be common following DBS. We listed a number of strategies for advancing research, highlighting opportunities related to personality conceptualization, personality assessment, and interdisciplinary scholarship. Finally, we offer practical applications of our findings for the informed consent process and for ongoing treatment.

Keywords: personality, deep brain stimulation, personality change, Parkinson's disease, personality pathology

\section{DOES PERSONALITY CHANGE FOLLOW DEEP BRAIN STIMULATION IN PARKINSON'S DISEASE PATIENTS?}

Parkinson's disease (PD) is a progressive neurodegenerative disorder affecting $\sim 3$ per 1,000 people over age 40 (Pringsheim et al., 2014). Classic symptoms of PD include tremor, bradykinesia, rigidity, and postural instability (Jankovic, 2008). There has been growing recognition of the importance of non-motor symptoms in PD (which vary in prevalence across different stages of 
the disease), including sensory processing difficulties, sleep problems, pain, autonomic changes, anxiety, depression, diminished initiative, psychotic symptoms, and dementia (Pandya et al., 2008; Löhle et al., 2009). The primary classic morphological indicator of $\mathrm{PD}$ is the loss of pigmented neurons in the substantia nigra pars compacta reflecting loss of dopaminergic neurons; however, neuropathological studies have documented that the disease involves multiple brain regions and neurotransmitter systems as it progresses (Brak et al., 2006; Dickson, 2012) consistent with the diverse symptoms associated with the disease.

First line treatments for PD involve dopaminergic medications (i.e., levodopa or dopamine agonists) to address motor symptoms (Rogers et al., 2017). If medication does not control motor symptoms or produces intolerable side effects, deep brain stimulation (DBS) may be considered as a treatment option. The most common site for DBS in the treatment of motor symptoms of PD is the subthalamic nucleus to address most cardinal motor symptoms of PD as well as reduce medication burden, although the ventral intermediate nucleus of the thalamus (to address tremor-predominant PD) or globus pallidus interna (when patients are highly susceptible to dyskinesias) may also be considered depending on the specific symptom profile, team preferences, and other factors (Rezai et al., 2008; Groiss et al., 2009). DBS entails surgical implantation of electrodes to deliver stimulation to specific brain regions. The electrodes are connected to a neuropacemaker that can be programmed by a clinician to deliver electrical stimulation at different amplitudes, pulse width (i.e., average power), and frequency. DBS has several advantages over previous ablative neurosurgical treatments for PD. First, it is reversible (i.e., the entire system can be explanted) and provides the treatment team the opportunity to maximize benefit while minimizing any potential side-effects via virtually unlimited programming options (Rezai et al., 2008). Finally, the patient is able to turn the DBS system on and off (Pugh, 2019). The safety and efficacy of DBS in treating many motor symptoms of PD has been well-demonstrated [see Deuschl et al. (2006b), Rezai et al. (2008), Weaver et al. (2009), and Limousin and Foltynie (2019)] with relatively mild cognitive risks in well-selected patients (Woods et al., 2002; Voon et al., 2006). However, DBS is not a panacea for PD and does not directly address all symptoms, particularly non-motor symptoms (Rezai et al., 2008).

\section{POTENTIAL PSYCHOLOGICAL EFFECTS OF DBS}

The past 15 years have seen an increasing amount of research devoted to whether DBS causes psychological changes in PD patients. Such effects are plausible for at least three reasons. First, DBS may impact cognitive, emotional, behavioral, and neuropsychiatic networks because these functional networks are adjacent to the motor fronto-subcortical networks targeted by DBS (Alexander et al., 1986; Cummings, 1993; Lanciego et al., 2012; Mosley et al., 2020). Second, living with technological equipment in the brain that alters functioning may present profound challenges to identity (e.g., Hildt, 2006; Schechtman, 2010; Witt et al., 2013). Third, the potential lifestyle changes (e.g., occupational, relational) that occur following DBS may relate to shifting patterns of psychosocial functioning (Deuschl et al., 2006a).

Excellent review articles touch upon the psychological effects of DBS, focusing on issues such as impulsivity (Jahanshahi et al., 2015), psychological variables relevant to neuroethics (Gilbert et al., 2018), acute and enduring psychiatric and neuropsychiatric changes (Castrioto et al., 2014; Kurtis et al., 2017), and measurement of these and other complex changes (Ineichen et al., 2016). Some of these articles reviewed individual studies that assessed variables relevant to the field of personality psychology, such as personality traits (Houeto et al., 2002), and personality disorders (Castelli et al., 2006), however, none of the reviews focused primarily on personality changes. Thus, our central aim is to provide a brief but relatively comprehensive evaluation of this research. Before doing so, it is important to frame our review within the context of three relevant issues: (a) defining personality and (b) offering a putative neurobiological basis for personality change following DBS.

\section{A MULTILAYER APPROACH TO DEFINING PERSONALITY}

Personality is broadly defined as a person's characteristic and relatively stable patterns of affect, behavior, cognition, and desire (the ABCDs of personality) over time and situation (Revelle et al., 2011). There have been several efforts to organize the abundant number of diverse individual differences subsumed by the field of personality psychology (e.g., McAdams and Pals, 2006; McCrae and Costa, 2008; DeYoung, 2015; Mayer, 2015). Though the particulars of these approaches are beyond the scope of this paper, we believe that a brief overview of an influential, multilayer approach (McAdams and Pals, 2006) will help with framing and interpreting research on the effects of DBS on personality. In this approach, at the most basic layer are a relatively small number of dispositional traits such as the Big Five [extraversion, agreeableness, conscientiousness, emotional stability (or neuroticism), and openness] and their lower order facets: Traits and facets are used to describe and explain the coherence and stability of ABCD patterns across time and situation. The second layer, characteristic adaptations, comprise motivational constructs (e.g., goals, values), developmental variables (e.g., attachment styles), and social attitudes (e.g., moral attitudes, prejudice) in which ABCD patterns are contextualized by time, situation, and/or social roles. The third layer, narrative identity, includes a person's self-authored life-stories connecting $\mathrm{ABCD}$ patterns from the past, present, and imagined future into an integrated whole that may provide a person with a sense of unity, coherence, and purpose ${ }^{1}$.

The three layers theoretically apply to both normal and pathological personality characteristics (McAdams, 2020). However, whereas assessments of normal personality span the

\footnotetext{
${ }^{1}$ We are intentionally excluding the other layers in this framework (evolution,
} culture) because they do not focus on individual differences. 
three levels, assessments of pathological personality may not. Measures of personality pathology focus predominantly on personality disorders, which are defined as "an enduring pattern of inner experience and behavior that deviates markedly from the expectations of the individual's culture, is pervasive and inflexible, has an onset in adolescence or early adulthood, is stable over time, and leads to distress or impairment" (American Psychiatric Association, p. 645). Even though personality disorders affect the whole person, and therefore may reflect dysfunction at the three layers of personality described above, assessment of personality disorders typically focuses on routine patterns of ABCDs (i.e., dispositional traits; Nuzum et al., 2019), and conceptualizations of personality pathology as maladaptive personality traits are gaining influence (e.g., Pocnet et al., 2018; Bagby and Widiger, 2020). Thus, existing personality pathology variables may be viewed as reflecting dispositional traits.

We will classify variables according to the levels of dispositional traits, characteristic adaptations, and narrative identity, when possible. We find this potentially useful for at least three reasons. First, it will illustrate which kinds of variables have received research attention and which have not, thereby possibly identifying areas in need of future research. Second, it may reveal which kinds of variables are more likely to change (for better or worse) or stay the same following DBS. Third, it may help improve the informed consent process for DBS; knowledge about what kind of personality characteristics might change could be helpful to the patient and the clinical team during discussions about the potential treatment risks and benefits.

Finally, we note two important exclusions from the multilayer framework for personality. First, this approach excludes neuropsychiatric disorders outside of personality disorders (e.g., depressive disorders, impulse control disorders, psychotic disorders, substance-related disorders, etc.). Though many psychiatric conditions entail significant and enduring disruptions in ABCDs and cannot be cleanly demarcated from personality, a thorough consideration of which disorders may include personality components is beyond the scope of this paper, and thus we chose to focus on personality disorders (and maladaptive personality traits). Second, the multilayer approach does not encompass cognitive dysfunction in areas such as attention, learning, memory, and executive function (Sahakian et al., 2015) which are known to be related to neural networks associated with variables related to personality such as initiative/drive, mood, and emotion regulation. Castrioto et al. (2014) and Kurtis et al. (2017) cover the effects of DBS on psychiatric and cognitive conditions comprehensively.

\section{PUTATIVE NEUROLOGICAL BASIS OF PERSONALITY CHANGE FOLLOWING DBS IN PD}

Without underestimating the psychosocial effects of DBS, neurobiological changes associated with DBS may be associated with changes involving any of the personality layers described above. Though DBS modulation specifically targets basal ganglia motor regions, the proximity of non-motor fiber networks to motor networks in the basal ganglia coupled with the intimate connections between the basal ganglia and limbic areas (Lanciego et al., 2012) makes it possible that DBS could modulate nonmotor neurobehavioral circuitry and functions as well. DBS for the treatment of motor symptoms of PD targets nodes along a motor cortical-basal ganglia-thalamo-cortical loop. The motor loop runs parallel to other cortico-basal ganglia-thalamo-cortical loops including a cognitive loop primarily associated with executive cognitive function (including emotion regulation) and two limbic loops originating in the orbitofrontal region (which is broadly associated with emotion) and anterior cingulate region (which is broadly associated with inhibition/disinhibition) [see Alexander et al. (1986) and Cummings (1993) for classic references]. Consequently, DBS stimulation in motor regions of the basal ganglia might theoretically spread to non-motor fiber pathways and result in neurobehavioral symptoms related to emotion regulation, motivation, and disinhibition. Case studies provide examples of these potential side-effect which are most often quickly addressed by altering stimulation parameters (e.g., Bejjani et al., 1999; Herzog et al., 2003; Wojtecki et al., 2007). Neuroimaging studies also support the role of the basal ganglia in emotional behavior and disorders more broadly [see Phillips et al. (2003a) and Phillips et al. (2003b)]. For example, regions in the basal ganglia are part of neural networks that have been linked to the personality trait of neuroticism (DeYoung et al., 2010), as well as psychiatric disorders relevant to neuroticism such as depression, anxiety disorders and phobias, and obsessive compulsive disorder (Kopell and Greenberg, 2008; Tremblay et al., 2015). Computational modeling has shown that the subthalamic nucleus is directly linked to impulsivity (Frank et al., 2007). DBS in the subthalamic has been associated with activation of regions of the limbic system, which is known to be central in emotional processing (Ulla et al., 2011). These observations just scratch the surface of potential effects of DBS on behaviors highly associated with the construct of personality.

\section{PD AND MEDICATIONS FOR PD MAY AFFECT PERSONALITY}

A diagnosis of PD has been associated with a personality profile characterized by low levels of impulsivity, flexibility, and noveltyseeking, as well as high levels of industriousness, cautiousness, and harm avoidance [see Poletti and Bonuccelli (2012), Santangelo et al. (2017), and Cerasa (2018)]. Neuropsychiatric symptoms associated with the underlying neuropathological changes of $\mathrm{PD}$, such as depression, anxiety, and apathy (Pandya et al., 2008), are commonly seen with estimates ranges from $30-40 \%$ for depression or anxiety to $17-70 \%$ for apathy (Chaudhuri et al., 2006; Aarsland et al., 2009). Such changes may affect personality ratings, especially those including negative emotions. Consequently, changes in personality over the course of DBS treatment may be difficult to disentangle from the underlying disease.

Pharmacological treatments for PD may also cause changes in personality and psychiatric symptoms. Levodopa and dopamine agonists are associated with impulsivity and 
reward-seeking behaviors (Lhommée et al., 2017), as well as impulse control disorder symptoms, including increased gorging of sweets, gambling/increased spending, increased hobbyism, and hypersexuality in some patients (Weintraub et al., 2010). In addition, dopaminergic medications can improve symptoms of apathy. Reductions in dopaminergic medications following successful DBS therapy have been associated with increased symptoms of apathy (Rossi et al., 2018). Relatedly, anti-depressants and anti-anxiety medications are frequently prescribed to alleviate psychological symptoms associated with PD. Changes in psychotropic medications and/or ongoing psychotropic medication management in patients may make it difficult to pinpoint the unique effects of DBS on psychiatric symptoms.

Disentangling the potential impact of underlying disease and potential medication effects on personality is further complicated by including the variable of time. As noted, PD is a progressive neurodegenerative disorder associated with the development and/or worsening of symptoms over time which may result in ongoing changes in medications. As motor symptoms increase, patients' relationships with family members and their ability to engage in important activities (e.g., work, drive) can be impacted which may contribute to personality changes (e.g., decreased feelings of confidence, sadness associated with various losses). Thus, assessment of personality changes in patients who are undergoing DBS therapy is complicated and requires a clear understanding of the underlying disease, typical neurobehavioral symptom onset timeline, and role of different treatments on relevant variables associated with the broad construct of personality.

\section{REVIEW OF EMPIRICAL RESEARCH}

Against this complicated backdrop, we examine empirical evidence pertaining to personality change following DBS. We evaluate the types of methods used to study this question, and we summarize and integrate research findings across personality characteristics. Finally, we list a number of strategies for advancing research.

\section{Inclusion Criteria and Search Strategy}

We included articles that met the following criteria: (a) metaanalyses and primary studies including PD patients who had undergone DBS that (b) assessed personality characteristics encompassed by the multilayer framework (McAdams and Pals, 2006) described previously. To compile our list of articles, we (a) relied on previous knowledge of the relevant research, (b) conducted searches on Google Scholar including (but not limited to) the terms "Deep Brain Stimulation," "DBS," "Parkinson's Disease," "personality," and "personality change" (both in isolation and combination), and (c) used connectedpapers.com to discover relevant papers that cited (or were cited by) articles we decided to include in the review.

\section{Methods for Assessing Personality Changes Following DBS}

Supplementary Table 1 gives detailed descriptions of studies (and their relevant results) included in our review, grouped according to primary methods. Most research used quantitative methods, while qualitative methods are growing increasingly common. There is an emerging trend for studies to assess patient valued characteristics using a mixed-methods approach. Across methods, most studies relied only on self-reports, though a few assessed caregiver or clinician perspectives.

\section{Quantitative Methods}

Quantitative research on personality change comes from (a) meta-analyses and (b) primary studies employing retrospective, cross-sectional, prospective, and randomized clinical trial (RCT) designs. This research has some general limitations. Metaanalyses focused mainly on clinical measures of psychiatric symptoms rather than scales assessing normal range personality. Most retrospective, cross-sectional, and prospective studies included small sample sizes, limiting power to detect small- to moderate effect sizes. And there has been one RCT to date, which decreases the confidence with which causal claims can be made. Additionally, quantitative studies focused almost exclusively on dispositional traits (using a wide variety of measures) rather than characteristic adaptations and narrative identity.

Though quantitative research using standardized scales has generated the most knowledge about personality change following DBS, there are at least two limitations to this method that may be particularly relevant to DBS patients. First, there is no opportunity for patients to elaborate on the personal relevance of the characteristics that are assessed. Relatedly, standardized scales, because they assess predetermined constructs rather than patient-defined variables, may not capture some of the personality characteristics that are viewed as most salient to the lived experience of patients (Nisenzon et al., 2011; Kubu and Ford, 2012). Thus, standardized scales might not fully assess the rich, idiosyncratic, and nuanced experience of patients.

\section{Qualitative Methods}

Given the relatively rare and unique experience of undergoing DBS for PD, it is important to gain a more personalized account of perceptions of personality change. Qualitative assessments have the potential to redress the limitations noted above. Asking open-ended questions gives patients opportunities to identify important characteristics that standardized assessments exclude and provides time for elaborating regarding why those characteristics are relevant to the patient's life. The five qualitative studies in Supplementary Table 1 employed semistructured interviews and coding techniques to identify salient themes relevant to personality change: Together, these studies revealed perceived personality changes that could be categorized across dispositional traits, characteristic adaptations, and narrative identity.

The strengths noted above should be balanced against the limitations inherent in qualitative methods, such as the biases of the research team, as well as limited replicability and generalizability (Creswell and Poth, 2016). Researcher bias is inherent to qualitative methods; for instance, researchers may prefer a certain theoretical framework and tend to code for characteristics consistent with that framework. Limited replicability is due in part to intensive coding that makes only small sample sizes feasible. In turn, small sample sizes 
limit the types of claims that can be made; for instance, most qualitative studies in Supplementary Table 1 showed that patients perceived personality changes in positive and negative directions but did not generate claims regarding whether positive or negative changes were more likely. The limited generalizability is because open-ended responses lack the standardization of scales that allows for making valid comparisons of results across multiple samples.

\section{Patient Valued Characteristics: A Mixed Methods Approach}

An emerging trend in DBS research, the use of quantitative measures of patient-valued characteristics [see, e.g., Kubu et al. (2019)], attempts to blend the strengths and mitigate the limitations of quantitative and qualitative research. Patients (and sometimes their caregivers) are consulted about what constitutes important values, goals, and/or traits, which may be rated on quantitative scales over the course of treatment (Kubu and Ford, 2012). Thus, this method may have the potential to capture what patients care about qualitatively and produce replicable and generalizable quantitative data. Other areas of research are beginning to incorporate patients' lived experiences into protocols to determine what patients value (Ghosh et al., 2021). Few studies have used mixed methods to study patient valued characteristics, and all focused on characteristic adaptations.

\section{Summary of Findings}

Research has assessed a wide range of personality variables (see Table 1). Only a few studies at most address any one variable, and thus all claims below may be viewed as preliminary. Most research involved relatively small sample sizes, and thus only the strongest effects are likely to have been detected. Furthermore, the lack of RCTs hampers causal inferences; though the focal outcome variables of RCTs will likely always be more directly clinically relevant (e.g., neuropsychiatric symptoms) than personality changes, future research may assess personality in conjunction with focal outcomes. With these caveats in mind, we turn to a review of extant findings.

By far the most work has been done at the level of dispositional traits. Given the popularity of assessing the Big Five in general (John et al., 2008), it is somewhat surprising that comparatively more research used inventories relevant to Cloninger's personality theory (Cloninger et al., 1993), such as the Temperament Character Inventory (Cloninger et al., 1994) and Tridimensional Personality Questionnaire (Cloninger et al., 1991). Outside of those approaches, several studies examined other affective (e.g., positive and negative affect, anxiety, and apathy) and behavioral (e.g., aggressiveness, hypersexuality, and impulsiveness) traits, and meta-analyses and a couple of other studies assessed personality pathology. Perhaps the most consistent finding is that, across normal range traits (Cloninger's traits, Big Five traits, and other affective/behavioral traits) and personality pathology, many studies found no evidence of change or mixed evidence regarding change, with an occasional study reporting only an increase or decrease in a given trait. Thus, there is very little evidence that any dispositional traits change following DBS.

Though research on characteristic adaptations is relatively sparse, this work shows somewhat consistent associations between DBS and improvements in abilities to carry out a variety of role-specific behaviors across a number of domains: routine, work, social/relational, and leisure. These findings point to the possibility that perhaps personality changes following DBS may be more common at level of characteristic adaptations than dispositional traits. We are hesitant to make stronger claims until more research has been done on characteristic adaptations.

Very little work has tapped constructs relevant to narrative identity. Findings from two qualitative studies suggest that issues around self-image and self-estrangement may be common for DBS patients: Some patients perceived improvements in these areas, whereas others perceived deficits.

\section{WAYS FORWARD}

In addition to calling for larger sample sizes and RCTs that assess personality variables (while recognizing the challenges of instituting those design features for the population in question), we offer six suggestions for advancing research. First, we suggest taking a step back from studies that typically rely on one personality inventory (or one qualitative method) to assess personality change; rather, it may be fruitful to frame research within integrative personality frameworks that define and describe interrelations between different parts of personality, such as traits, contextualized roles, and identity (e.g., McAdams and Pals, 2006; McCrae and Costa, 2008; Mayer, 2015). Doing so may help to organize current findings and identify aspects of personality that have previously been overlooked. Second, it is clear that dispositional traits assessed by quantitative instruments have received the most research attention, so we encourage future studies on more contextualized aspects of personality and identity while taking into account the patient's opinions on valued personality characteristics. Third, most research has relied on the patient's perceptions of personality alone or, in the case of personality pathology, a clinician's rating; because the patient, caregivers, and clinicians all provide invaluable viewpoints, we encourage studies assessing personality from multiple perspectives (Goering et al., 2017). Fourth, as DBS for PD spans multiple areas of expertise in scholarship and practice (e.g., medicine, surgery, neuroscience, clinical neuropsychology, psychopathology, personality, and neuroethics just to name a few), interdisciplinary scholarship is a necessity (Kubu and Ford, 2012; Kubu et al., 2019). Fifth, and related to the prior four points, we believe that perhaps the most crucial advances will come from interdisciplinary efforts to design and validate new assessments capable of measuring complex personality changes across various constructs and multiple raters (Kubu and Ford, 2012; Ineichen et al., 2016). Sixth, integration of research on DBS and personality change for other conditions, such as epilepsy (Gilbert, 2012), primary dystonia (Hariz et al., 2011), Tourette's 
TABLE 1 | Summary of findings organized by layers of personality and variables.

Layer of personality Variables

Dispositional traits

Cloninger's Personality Theory Traits

Novelty-seeking

Harm avoidance

Reward dependence

Persistence

Self-directedness

Cooperativeness

Self-transcendence

Big Five Traits

Extraversion

Agreeableness

Conscientiousness

Neuroticism

Openness

Affective/Behavioral Traits

Negative affective traits

Positive affective traits

Aggressiveness

Anxiety

Apathy

Hypersexuality

Hypomania

Impulsivity

\section{Personality Pathology}

General personality pathology

Personality disorders: obsessive-compulsive, paranoid

Personailty disorders: avoidant, dependant, passive-aggressive, self-frustrating, schizotypal, schizoid, histrionic, narcisssistic, borderline, and antisocial
Associations between DBS and variables

-/O: Lhommée et al. (2017) - Quant/P

0: Houeto et al. (2006) - Quant/P; Pham et al. (2015) - Quant/P

0/+: Fassino et al. (2010) - Quant/P

0: Houeto et al. (2006) - Quant/P; Fassino et al. (2010) - Quant/P; Pham et al. (2015)

- Quant/P

+: Lhommée et al. (2017) - Quant/P

-/0: Lhommée et al. (2017) - Quant/P

0: Houeto et al. (2006) - Quant/P; Fassino et al. (2010) - Quant/P; Pham et al. (2015)

- Quant/P

-: Pham et al. (2015) - Quant/P

0: Houeto et al. (2006) - Quant/P; Fassino et al. (2010) - Quant/P

0: Houeto et al. (2006) - Quant/P; Fassino et al. (2010) - Quant/P; Pham et al. (2015)

- Quant/P

O: Houeto et al. (2006) - Quant/P; Fassino et al. (2010) - Quant/P; Pham et al. (2015)

- Quant/P

-: Pham et al. (2015) - Quant/P

0: Houeto et al. (2006) - Quant/P

0/+: Fassino et al. (2010) - Quant/P

-/0: Boel et al. (2016) - Quant/RCT

-/O: Boel et al. (2016) - Quant/RCT

0: Boel et al. (2016) - Quant/RCT

0: Pham et al. (2015) - Quant/P; Boel et al. (2016) - Quant/RCT

-/0: Boel et al. (2016) - Quant/RCT

-/+: Gilbert (2018) - Qual; Thomson et al. (2019) - Qual

0/+: Thomson et al. (2019) - Qual

-/+: Gilbert (2018) - Qual; Thomson et al. (2020) - Qual

0: Temel et al. (2006) - Quant/MA

0: Castelli et al. (2006) - Quant/P

0: Temel et al. (2006) - Quant/MA; Appleby et al. (2007) - Quant/MA

+: Denheyer et al. (2009) - Quant/Ret; Gilbert (2012) - Qual

0: Temel et al. (2006) - Quant/MA; Appleby et al. (2007) - Quant/MA

+: Lewis et al. (2015) - Quant/P

0: Lewis et al. (2015) - Quant/P

O/+: Pham et al. (2015) - Quant/P

+: Hälbig et al. (2009) - Quant/CS

0: Temel et al. (2006) - Quant/MA; Appleby et al. (2007) - Quant/MA;

-/+: Houeto et al. (2002) - Quant/Ret

-: Castelli et al. (2006) - Quant/P

0: Castelli et al. (2006) - Quant/P

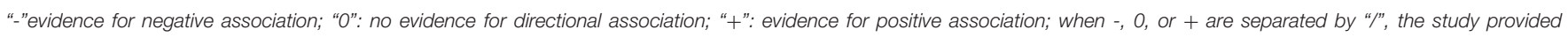

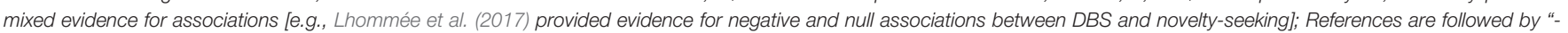

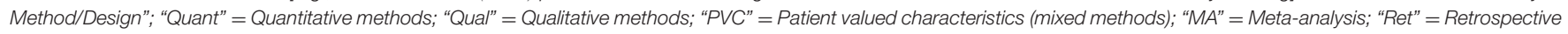
design; "CS" = Cross-sectional design; "P" = prospective design; "RCT" = Randomized clinical trial.

Syndrome (Schoenberg et al., 2015), OCD (de Haan et al., 2013, 2015), and others will help to identify DBS effects that generalize and those that are unique to PD.
In conclusion we offer two ways in which the findings of this review may be applied. First, we advocate for interdisciplinary work applying findings regarding personality change to improve 
the informed consent process; patient expectations and goals regarding personality change can be assessed and compared to the current state of knowledge, which may lead to enhanced communication and collaboration among patients and interdisciplinary treatment teams and ultimately better decisions about whether to pursue DBS. Further, the findings may help treatment teams to assess and manage patient expectations throughout the course of treatment; guiding patients to endorse and then maintain realistic expectations regarding personality change may guard against overly negative and potentially harmful reactions to unmet expectations.

\section{AUTHOR CONTRIBUTIONS}

JW wrote the manuscript. CK and AM revised the manuscript and provided critical comments on the manuscript. JZ and MM

\section{REFERENCES}

Aarsland, D., Marsh, L., and Schrag, A. (2009). Neuropsychiatric symptoms in Parkinson's disease. Mov. Disord. Off. J. Mov. Disord. Soc. 24, 2175-2186. doi: $10.1002 / \mathrm{mds} .22589$

Alexander, G. E., De Long, M. R., and Strick, P. L. (1986). Parallel organization of functionally segregated circuits linking basal ganglia and cortex. Ann. Rev. Neurosci. 9, 357-381. doi: 10.1146/annurev.ne.09.030186.002041

Appleby, B. S., Duggan, P. S., Regenberg, A., and Rabins, P. V. (2007). Psychiatric and neuropsychiatric adverse events associated with deep brain stimulation: a meta-analysis of ten years' experience. Mov. Disord. Off. J. Mov. Disord. Soc. 22, 1722-1728. doi: $10.1002 / \mathrm{mds} .21551$

Bagby, R. M., and Widiger, T. A. (2020). Assessment of the ICD-11 dimensional trait model: an introduction to the special section. Psychol. Assess. 32, 1-7. doi: $10.1037 /$ pas0000785

Barrash, J., Anderson, S. W., Jones, R. D., and Tranel, D. (1997). The Iowa rating scales of personality change: reliability and validity. J. Int. Neuropsychol. Soc. 3, 27-28.

Baumann-Vogel, H., Bodenmann, G., Schmid, J., Waldvogel, D., Ineichen, C., and Baumann, C. R. (2020). Partners' view after subthalamic deep brain stimulation: better relationships despite patients being less active. Clin. Parkinson. Relat. Disord. 3:100052. doi: 10.1016/j.prdoa.2020.100052

Bejjani, B. P., Damier, P., Arnulf, I., Thivard, L., Bonnet, A. M., Dormont, D., et al. (1999). Transient acute depression induced by highfrequency deep-brain stimulation. N. Engl. J. Med. 340, 1476-1480. doi: 10.1056/NEJM199905133401905

Bodenmann, G. (2008). Dyadisches Coping Inventar (DCI) [Dyadic Coping Inventory]. Bern: Huber.

Boel, J. A., Odekerken, V. J., Geurtsen, G. J., Schmand, B. A., Cath, D. C., Figee, M., et al. (2016). Psychiatric and social outcome after deep brain stimulation for advanced Parkinson's disease. Mov. Disord. 31, 409-413. doi: $10.1002 / \mathrm{mds} .26468$

Braak, H., Bohl, J. R., Muller, C. M., Rub, U., de Vos, R. A. I., and Del Tredici, K. (2006). Stanley Fahn lecture 2005: the staging procedure for the inclusion body pathology associated with sporadic Parkinson's disease reconsidered. Mov. Disord. 21, 2042-2050. doi: 10.1002/mds.21065

Braun, V., and Clarke, V. (2006). Using thematic analysis in psychology. Qual. Res. Psychol, 3, 77-101. doi: 10.1191/1478088706qp063oa

Castelli, L., Perozzo, P., Zibetti, M., Crivelli, B., Morabito, U., Lanotte, M., et al. (2006). Chronic deep brain stimulation of the subthalamic nucleus for Parkinson's disease: effects on cognition, mood, anxiety and personality traits. Eur. Neurol. 55, 136-144. doi: 10.1159/ 000093213

Castrioto, A., Lhommée, E., Moro, E., and Krack, P. (2014). Mood and behavioural effects of subthalamic stimulation in Parkinson's disease. Lancet Neurol. 13, 287-305. doi: 10.1016/S1474-4422(13)70294-1 provided comments on the manuscript. All authors contributed to the article and approved the submitted version.

\section{ACKNOWLEDGMENTS}

We gratefully acknowledge funding support from the National Institute of Mental Health, Award Number R01MH114853 and from the National Institute of Neurological Disorders and Stroke, Award Number RC1NS068086.

\section{SUPPLEMENTARY MATERIAL}

The Supplementary Material for this article can be found online at: https://www.frontiersin.org/articles/10.3389/fpsyg. 2021.643277/full\#supplementary-material

Cerasa, A. (2018). Re-examining the Parkinsonian personality hypothesis: a systematic review. Pers. Individ. Dif. 130, 41-50. doi: 10.1016/j.paid.2018.03.045

Chaudhuri, K. R., Healy, D. G., and Schapira, A. H. (2006). Non-motor symptoms of Parkinson's disease: diagnosis and management. Lancet Neurol. 5, 235-245. doi: 10.1016/S1474-4422(06)70373-8

Cloninger, C., Svrakic, D. M., and Przybeck, T. R. (1993). A psychobiological model of temperament and character. Arch. Gen. Psychiatry 50, 975-990.

Cloninger, C. R. (1999). The Temperament and Character Inventory-Revised. St Louis, MO: Center for Psychobiology of Personality, Washington University.

Cloninger, C. R., Przybeck, T. R., and Svrakic, D. M. (1991). The tridimensional personality questionnaire: US normative data. Psychol. Rep. 69, 1047-1057.

Cloninger, C. R., Przybeck, T. R., Svrakic, D. M., and Wetzel, R. D. (1994). The Temperament and Character Inventory (TCI): A Guide to Its Development and Use. St Louis, MO: Center for Psychobiology of Personality, Washington University.

Creswell, J. W., and Poth, C. N. (2016). Qualitative Inquiry and Research Design: Choosing Among Five Approaches. Thousand Oaks, CA: Sage publications.

Cummings, J. L. (1993). Frontal-subcortical circuits and human behavior. Arch. Neurol. 50, 873-880. doi: 10.1001/archneur.1993.00540080076020

de Haan, S., Rietveld, E., Stokhof, M., and Denys, D. (2013). The phenomenology of deep brain stimulation-induced changes in OCD: an enactive affordance-based model. Front. Hum. Neurosci. 7:653. doi: 10.3389/fnhum.2013.00653

de Haan, S., Rietveld, E., Stokhof, M., and Denys, D. (2015). Effects of deep brain stimulation on the lived experience of Obsessive-Compulsive Disorder patients: in-depth interviews with 18 patients. PLoS ONE 10:e0135524. doi: 10.1371/journal.pone.0135524

Denheyer, M., Kiss, Z. H., and Haffenden, A. M. (2009). Behavioral effects of subthalamic deep brain stimulation in Parkinson's disease. Neuropsychologia 47, 3203-3209. doi: 10.1016/j.neuropsychologia.2009.07.022

Deuschl, G., Herzog, J., Kleiner-Fisman, G., Kubu, C., Lozano, A. M., Lyons, K. E., et al. (2006a). Deep brain stimulation: postoperative issues. Mov. Disord. Off. J. Mov. Disord. Soc. 21, S219-S237. doi: 10.1002/mds.20957

Deuschl, G., Schade-Brittinger, C., Krack, P., Volkmann J, Schäfer H, Bötzel K, et al. (2006b). A randomized trial of deep-brain stimulation for Parkinson's disease. N. Engl. J. Med. 355, 896-908. doi: 10.1056/NEJMoa060281

DeYoung, C. G. (2015). Cybernetic big five theory. J. Res. Pers. 56, 33-58. doi: 10.1016/j.jrp.2014.07.004

DeYoung, C. G., Hirsh, J. B., Shane, M. S., Papademetris, X., Rajeevan, N., and Gray, J. R. (2010). Testing predictions from personality neuroscience. Psychol. Sci. 21:820. doi: 10.1177/0956797610370159

Dickson, D. W. (2012). Parkinson's disease and parkinsonism: neuropathology. Cold Spring Harb. Perspect. Med. 2:a009258. doi: 10.1101/cshperspect.a009258

Fassino, S., Daga, G. A., Gramaglia, C., Piero, A., Zibetti, M., Castelli, L., et al. (2010). Novelty-Seeking in Parkinson's Disease after deep brain stimulation of the subthalamic nucleus: a case-control study. Psychosomatics 51, 62-67. doi: 10.1016/S0033-3182(10)70660-5 
Frank, M. J., Samanta, J., Moustafa, A. A., and Sherman, S. J. (2007). Hold your horses: impulsivity, deep brain stimulation, and medication in parkinsonism. Science 318, 1309-1312. doi: 10.1126/science.1146157

Ghosh, C. C., McVicar, D., Davidson, G., and Shannon, C. (2021). Measuring diagnostic heterogeneity using text-mining of the lived experiences of patients. BMC Psychiatry 21, 1-12. doi: 10.1186/s12888-021-03044-1

Gilbert, F. (2012). The burden of normality: from "chronically ill" to "symptom free." New ethical challenges for deep brain stimulation postoperative treatment. J. Med. Ethics 38, 408-412. doi: 10.1136/medethics-2011-100044

Gilbert, F. (2018). Deep brain stimulation: inducing self-estrangement. Neuroethics 11, 157-165. doi: 10.1007/s12152-017-9334-7

Gilbert, F., Goddard, E., Viaña, J. N. M., Carter, A., and Horne, M. (2017). I miss being me: phenomenological effects of deep brain stimulation. AJOB Neurosci. 8, 96-109. doi: 10.1080/21507740.2017.1320319

Gilbert, F., Viaña, J. N., and Ineichen, C. (2020). Deflating the deep brain stimulation causes personality changes bubble: the authors reply. Neuroethics. doi: 10.1007/s12152-020-09437-5

Gilbert, F., Viaña, J. N. M., and Ineichen, C. (2018). Deflating the "DBS causes personality changes" bubble. Neuroethics. doi: 10.1007/s12152-018-9386-3

Goering, S., Brown, T., and Alsarraf, J. (2017). Others' contributions to narrative identity matter. AJOB Neurosci. 8, 176-178. doi: 10.1080/21507740.2017.1366586

Groiss, S. J., Wojtecki, L., Südmeyer, M., and Schnitzler, A. (2009). Deep brain stimulation in Parkinson's disease. Ther. Adv. Neurol. Disord. 2, 20-28. doi: 10.1177/1756285609339382

Hälbig, T. D., Tse, W., Frisina, P. G., Baker, B. R., Hollander, E., Shapiro, H., et al. (2009). Subthalamic deep brain stimulation and impulse control in Parkinson's disease. Eur. J. Neurol. 16, 493-497. doi: 10.1111/j.1468-1331.2008. 02509.x

Hariz, G.-M., Limousin, P., Tisch, S., Jahanshahi, M., and Fjellman-Wiklund, A. (2011). Patients' perceptions of life shift after deep brain stimulation for primary dystonia-a qualitative study. Mov. Disord. 26, 2101-2106. doi: $10.1002 / \mathrm{mds} .23796$

Herzog, J., Reiff, J., Krack, P., Witt, K., Schrader, B., Müller, D., et al. (2003). Manic episode with psychotic symptoms induced by subthalamic nucleus stimulation in a patient with Parkinson's disease. Mov. Disord. Off. J. Mov. Disord. Soc. 18, 1382-1384. doi: 10.1002/mds. 10530

Hildt, E. (2006). Electrodes in the brain: some anthropological and ethical aspects of deep brain stimulation. Int. Rev. Inform. Ethics 5, 33-38. Available online at: http://informationethics.ca/index.php/irie/article/view/193

Houeto, J.-L., Mallet, L., Mesnage, V., Tezenas du Montcel, S., Béhar, C., Gargiulo, M., et al. (2006). Subthalamic stimulation in Parkinson Disease: behavior and social adaptation. JAMA Neurol. 63, 1090-1095. doi: 10.1001/archneur.63.8.1090

Houeto, J. L., Mesnage, V., Mallet, L., Pillon, B., Gargiulo, M., du Moncel, S. T., et al. (2002). Behavioural disorders, Parkinson's disease and subthalamic stimulation. J. Neurol. Neurosurg. Psychiatry 72:701. doi: 10.1136/jnnp.72.6.701

Ineichen, C., Baumann-Vogel, H., and Christen, M. (2016). Deep brain stimulation: in search of reliable instruments for assessing complex personalityrelated changes. Brain Sci. 6:40. doi: 10.3390/brainsci6030040

Jahanshahi, M., Obeso, I., Baunez, C., Alegre, M., and Krack, P. (2015). Parkinson's Disease, the subthalamic nucleus, inhibition, and impulsivity. Mov. Disord. 30, 128-140. doi: 10.1002/mds.26049

Jankovic, J. (2008). Parkinson's disease: clinical features and diagnosis. J. Neurol. Neurosurg. Psychiatry 79, 368-376. doi: 10.1136/jnnp.2007.131045

John, O. P., Robins, R. W., and Pervin, L. A. (2008). Handbook of Personality: Theory and Research, 3rd edn. New York, NY: Guilford Press.

Kliem, S., Job, A. K., Kröger, C., Bodenmann, G., Stöbel-Richter, Y., Hahlweg, K., et al. (2012). Entwicklung und Normierung einer Kurzform des Partnerschaftsfragebogens (PFB-K) an einer repräsentativen deutschen Stichprobe. Zeitschrift für Klinische Psychologie und Psychotherapie. 41, 81-89. doi: 10.1026/1616-3443/a000135

Kopell, B. H., and Greenberg, B. D. (2008). Anatomy and physiology of the basal ganglia: implications for DBS in psychiatry. Neurosci. Biobehav. Rev. 32, 408-422. doi: 10.1016/j.neubiorev.2007.07.004

Kubu, C. S., Cooper, S. E., Machado, A., Frazier, T., Vitek, J., and Ford, P. J. (2017a). Insights gleaned by measuring patients' stated goals for DBS: more than tremor. Neurology 88, 124-130. doi: 10.1212/WNL.0000000000003485
Kubu, C. S., and Ford, P. (2012). Beyond mere symptom relief in deep brain stimulation: an ethical obligation for multifaceted assessment of outcome. AJOB Neurosci. 3, 44-49. doi: 10.1080/21507740.2011.633960

Kubu, C. S., Ford, P. J., and Lapin, B. (2017b). Patients' Perceptions of Personality Change in Parkinson's Disease and Following Deep Brain Stimulation. Washington, DC: International Neuroethics Society meeting.

Kubu, C. S., Ford, P. J., Wilt, J. A., Merner, A. R., Montpetite, M., Zeigler, J., et al. (2019). Pragmatism and the importance of interdisciplinary teams in investigating personality changes following DBS. Neuroethics 2019:10.1007/s12152-019-09418-3. doi: 10.1007/s12152-019-09418-3

Kubu, C. S., Frazier, T., Cooper, S. E., Machado, A., Vitek, J., and Ford, P. J. (2018). Patients' shifting goals for deep brain stimulation and informed consent. Neurology 91, e472-e478. doi: 10.1212/WNL.0000000000005917

Kurtis, M. M., Rajah, T., Delgado, L. F., and Dafsari, H. S. (2017). The effect of deep brain stimulation on the non-motor symptoms of Parkinson's disease: a critical review of the current evidence. NPJ Parkinson's Dis. 3, 1-12. doi: 10.1038/npjparkd.2016.24

Lanciego, J. L., Luquin, N., and Obeso, J. A. (2012). Functional neuroanatomy of the basal ganglia. Cold Spring Harb. Perspectiv. Med. 2:a009621. doi: 10.1101/cshperspect.a009621

Lewis, C. J., Maier, F., Horstkötter, N., Zywczok, A., Witt, K., Eggers, C., et al. (2015). Subjectively perceived personality and mood changes associated with subthalamic stimulation in patients with Parkinson's disease. Psychol. Med. 45, 73-85. doi: 10.1017/S0033291714001081

Lhommée, E., Boyer, F., Wack, M., Pélissier, P., Klinger, H., Schmitt, E., et al. (2017). Personality, dopamine, and Parkinson's disease: insights from subthalamic stimulation. Mov. Disord. 32, 1191-1200. doi: 10.1002/mds.27065

Limousin, P., and Foltynie, T. (2019). Long-term outcomes of deep brain stimulation in Parkinson disease. Nat. Rev. Neurol. 15, 234-242. doi: 10.1038/s41582-019-0145-9

Löhle, M., Storch, A., and Reichmann, H. (2009). Beyond tremor and rigidity: non-motor features of Parkinson's disease. J. Neural Transmission 116:1483. doi: 10.1007/s00702-009-0274-1

Mayer, J. D. (2015). The personality systems framework: current theory and development. J. Res. Personal. 56, 4-14. doi: 10.1016/j.jrp.2015.01.001

McAdams, D. P. (2020). Psychopathology and the self: human actors, agents, and authors. J. Personal. 88, 146-155. doi: 10.1111/jopy.12496

McAdams, D. P., and Pals, J. L. (2006). A new big five: fundamental principles for an integrative science of personality. Am. Psychol. 61, 204-217. doi: 10.1037/0003-066X.61.3.204

McCrae, R. R., and Costa, P. T. (2008). "The five-factor theory of personality," in Handbook of Personality: Theory and Research, 3 edn, eds O. P. John, R. W. Robins, and L. A. Pervin (Guilford Press), 159-181.

Mosley, P. E., Paliwal, S., Robinson, K., Coyne, T., Silburn, P., Tittgemeyer, M., et al. (2020). The structural connectivity of subthalamic deep brain stimulation correlates with impulsivity in Parkinson's disease. Brain 143, 2235-2254. doi: 10.1093/brain/awaa148

Nisenzon, A. N., Robinson, M. E., Bowers, D., Banou, E., Malaty, I., and Okun, M. S. (2011). Measurement of patient-centered outcomes in Parkinson's disease: what do patients really want from their treatment? Parkinson. Relat. Disord. 17, 89-94. doi: 10.1016/j.parkreldis.2010.09.005

Nuzum, H., Shapiro, J. L., and Clark, L. A. (2019). Affect, behavior, and cognition in personality and functioning: an item-content approach to clarifying empirical overlap. Psychol. Assess. 31, 905-912. doi: 10.1037/pas0000712

Pandya, M., Kubu, C., and Giroux, M. (2008). The many faces of Parkinson's disease: not just a movement disorder. Cleveland Clin. J. Med. 75, 856-864. doi: 10.3949/ccjm.75a.07005

Patton, J. H., Stanford, M. S., and Barratt, E. S. (1995). Factor structure of the Barratt impulsiveness scale. J. Clin. Psychol. 51, 768-774. doi: 10.1002/1097-4679(199511)51:6<768::AID-JCLP2270510607>3.0.CO;2-1

Pham, U., Solbakk, A.-K., Skogseid, I.-M., Toft, M., Pripp, A. H., Konglund, A. E., et al. (2015). Personality changes after deep brain stimulation in Parkinson's Disease. Parkinson's Dis. 7:490507. doi: 10.1155/2015/ 490507

Phillips, M. L., Drevets, W. C., Rauch, S. L., and Lane, R. (2003a). Neurobiology of emotion perception I: the neural basis of normal emotion perception. Biol. Psychiatry 54, 504-514. doi: 10.1016/S0006-3223(03) 00168-9 
Phillips, M. L., Drevets, W. C., Rauch, S. L., and Lane, R. (2003b). Neurobiology of emotion perception II: implications for major psychiatric disorders. Biol. Psychiatry 54, 515-528. doi: 10.1016/S0006-3223(03)00171-9

Pocnet, C., Antonietti, J.-P., Handschin, P., Massoudi, K., and Rossier, J. (2018). The many faces of personality: the DSM-5 dimensional and categorical models and the five-factor model. Personal. Individ. Diff. 121, 11-18. doi: 10.1016/j.paid.2017.09.005

Poletti, M., and Bonuccelli, U. (2012). Personality traits in patients with Parkinson's disease: assessment and clinical implications. J. Neurol. 259, 1029-1038. doi: 10.1007/s00415-011-6302-8

Pringsheim, T., Jette, N., Frolkis, A., and Steeves, T. D. (2014). The prevalence of Parkinson's disease: a systematic review and meta-analysis. Mov. Disord. 29, 1583-1590. doi: 10.1002/mds. 25945

Pugh, J. (2019). No going back? Reversibility and why it matters for deep brain stimulation. J. Med. Ethics 45, 225-230. doi: 10.1136/medethics-2018-105139

Revelle, W., Wilt, J., and Condon, D. M. (2011). "Individual differences and differential psychology: a brief history and prospect," in The WileyBlackwell Handbook of Individual Differences, 2nd edn, eds T. ChamorroPremuzic, A. Furnham, and S. von Stumm (Wiley-Blackwell), 3-38. doi: 10.1002/9781444343120.ch1

Rezai, A. R., Machado, A. G., Deogaonkar, M., Azmi, H., Kubu, C., and Boulis, N. M. (2008). Surgery for movement disorders. Neurosurgery 62(Suppl.2), 809-839. doi: 10.1227/01.neu.0000316285.52865.53

Rogers, G., Davies, D., Pink, J., and Cooper, P. (2017). Parkinson's disease: summary of updated NICE guidance. BMJ 358:j1951. doi: 10.1136/bmj.j1951

Rossi, M., Bruno, V., Arena, J., Cammarota, Á., and Merello, M. (2018). Challenges in PD patient management after DBS: a pragmatic review. Mov. Disord. Clin. Pract. 5, 246-254 doi: 10.1002/mdc3.12592

Sahakian, B. J., Bruhl, A. B., Cook, J., Killikelly, C., Savulich, G., Piercy, T., et al. (2015). The impact of neuroscience on society: cognitive enhancement in neuropsychiatric disorders and in healthy people. Philos. Trans. Royal Soc. B Biol. Sci. 370:20140214. doi: 10.1098/rstb.2014.0214

Santangelo, G., Piscopo, F., Barone, P., and Vitale, C. (2017). Personality in Parkinson's disease: clinical, behavioural and cognitive correlates. J. Neurol. Sci. 374, 17-25. doi: 10.1016/j.jns.2017.01.013

Schechtman, M. (2010). Philosophical reflections on narrative and deep brain stimulation. J. Clin. Ethics 21:133.

Schoenberg, M. R., Maddux, B. N., Riley, D. E., Whitney, C. M., Ogrocki, P. K., Gould, D., et al. (2015). Five-months-postoperative neuropsychological outcome from a pilot prospective randomized clinical trial of thalamic deep brain stimulation for Tourette Syndrome. Neuromodulation 18, 97-104. doi: $10.1111 /$ ner.12233

Spielberger, C. D., Gorsuch, R. L., and Luchene, R. E. (1970). The State-Trait Anxiety Inventory. Palo Alto, CA: Consulting Psychologists Press.

Spitzer, R. L., Williams, J. B., Gibbon, M., and First, M. B. (1992). The structured clinical interview for DSM-III-R (SCID): I: history, rationale, and description. Archiv. Gen. Psychiatry 49, 624-629.

Temel, Y., Kessels, A., Tan, S., Topdag, A., Boon, P., and Visser-Vandewalle, V. (2006). Behavioural changes after bilateral subthalamic stimulation in advanced Parkinson disease: a systematic review. Parkinson. Relat. Disord. 12, 265-272. doi: 10.1016/j.parkreldis.2006.01.004

Thomson, C. J., Segrave, R. A., and Carter, A. (2019). Changes in personality associated with deep brain stimulation: a qualitative evaluation of clinician perspectives. Neuroethics 2, 1-16. doi: 10.1007/s12152-019-09419-2

Thomson, C. J., Segrave, R. A., Racine, E., Warren, N., Thyagarajan, D., and Carter, A. (2020). "He's back so I'm not alone": the impact of deep brain stimulation on personality, self, and relationships in Parkinson's Disease. Qualitat. Health Res. 2020:1049732320951144. doi: 10.1177/1049732320951144

Törnqvist, A., Ahlström, G., Widner, H., and Rehncrona, S. (2007). Fulfilment of patients' goals after thalamic deep brain stimulation: a follow-up study. Parkinson. Relat. Disord. 13, 29-34. doi: 10.1016/j.parkreldis.2006.06.005

Tremblay, L., Worbe, Y., Thobois, S., Sgambato-Faure, V., and Féger, J. (2015). Selective dysfunction of basal ganglia subterritories: from movement to behavioral disorders. Mov. Disord. 30, 1155-1170. doi: 10.1002/mds.26199

Ulla, M., Thobois, S., Llorca, P.-M., Derost, P., Lemaire, J.-J., Chereau-Boudet, I., et al. (2011). Contact dependent reproducible hypomania induced by deep brain stimulation in Parkinson's disease: clinical, anatomical and functional imaging study. J. Neurol. Neurosurg. Psychiatry 82, 607-614. doi: 10.1136/jnnp.2009.199323

Voon, V., Kubu, C. S., Krack, P., Houeto, J.-L., and Troster, A. I. (2006). Neuropsychiatric and cognitive issues in the evaluation of Parkinson's disease. Mov. Disord. 21, S305-S327. doi: 10.1002/mds.20963

Weaver, F. M., Follett, I., Stern, M., et al. (2009). Bilateral deep brain stimulation vs. best medical therapy for patients with advanced Parkinson disease: a randomized controlled trial. JAMA 301, 63-73. doi: 10.1001/jama.2008.929

Weintraub, D., Koester, J., Potenza, M. N., Siderowf, A. D., Stacy, M., Voon, V., et al. (2010). Impulse control disorder in Parkinson disease. A cross-sectional study of 3090 patients. Archiv. Neurol. 67, 589-595. doi: 10.1001/archneurol.2010.65

Whiteside, S. P., and Lynam, D. R. (2001). The Five Factor Model and impulsivity: using a structural model of personality to understand impulsivity. Personal. Individ. Diff. 30, 669-689. doi: 10.1016/S0191-8869(00)00064-7

Witt, K., Kuhn, J., Timmermann, L., Zurowski, M., and Woopen, C. (2013). Deep brain stimulation and the search for identity. Neuroethics 6, 499-511. doi: 10.1007/s12152-011-9100-1

Wojtecki, L., Nickel, J., Timmermann, L., Maarouf, M., Südmeyer, M., Schneider, F., et al. (2007). Pathological crying induced by deep brain stimulation. Mov. Disord. Off. J. Mov. Disord. Soc. 22, 1314-1316. doi: 10.1002/mds. 21266

Woods, S. P., Fields, J. A., and Troster, A. I. (2002). Neuropsychological sequelae of subthalamic nucleus deep brain stimulation in Parkinson's disease: a critical review. Neuropsychol. Rev. 12, 111-126. doi: 10.1023/A:10168067 11705

Conflict of Interest: The authors declare that the research was conducted in the absence of any commercial or financial relationships that could be construed as a potential conflict of interest.

Publisher's Note: All claims expressed in this article are solely those of the authors and do not necessarily represent those of their affiliated organizations, or those of the publisher, the editors and the reviewers. Any product that may be evaluated in this article, or claim that may be made by its manufacturer, is not guaranteed or endorsed by the publisher.

Copyright (c) 2021 Wilt, Merner, Zeigler, Montpetite and Kubu. This is an open-access article distributed under the terms of the Creative Commons Attribution License (CC $B Y)$. The use, distribution or reproduction in other forums is permitted, provided the original author(s) and the copyright owner(s) are credited and that the original publication in this journal is cited, in accordance with accepted academic practice. No use, distribution or reproduction is permitted which does not comply with these terms. 